\title{
Okçularda Tutuş ve Çekme Kollarının Omuz Eklemi Kas Kuvveti, Esneklik ve Propriosepsiyon Duyusunun Karşılaştırılması
}

\section{Comparison of Muscle Strength, Flexibility and Proprioception of Bow and Draw Arms in Archers}

\author{
${ }^{1}$ Banu KABAK \\ ${ }^{1}$ Tuğba KOCAHAN \\ ${ }^{1,2}$ Bihter AKINOĞLU \\ ${ }^{1}$ Adnan HASANOĞLU
}

${ }^{1}$ Gençlik ve Spor Bakanlığı, Spor Genel Müdürlüğü, Sağlık İşleri Dairesi Başkanlığı, Ankara, Türkiye

${ }^{2}$ Ankara Yıldırım Beyazıt Üniversitesi, Sağlık Bilimleri Fakültesi, Fizyoterapi ve Rehabilitasyon Bölümü, Ankara Türkiye

\section{Yazışma Adresi \\ Corresponding Address:}

\section{Dr. Arş. Gör. Bihter AKINOĞLU}

ORCID: 0000-0002-8214-7895

Ankara Yıldırım Beyazıt Üniversitesi, Sağlık Bilimleri Fakültesi, Fizyoterapi ve Rehabilitasyon Bölümü, 06760 Çubuk / ANKARA

E-posta: rgkardelen@yahoo.com
Geliş Tarihi (Received): 11.03.2019 Kabul Tarihi (Accepted): 17.03.2020

\section{öz}

Bu çalışmanın amacı okçularda çekiş kolu ile tutuş kolunun omuz eklemi izometrik kas kuvveti, esneklik ve propriyosepsiyon duyusunun incelenmesidir. Çalışmamıza milli takım düzeyinde 21 okçu (9 kadın, 12 erkek) katıldı. Sporcuların omuz abdüktör ve addüktör kaslarının izometrik kas kuvveti 90 abdüksiyon açısında IsoMed 2000 cihazı ile değerlendirildi. Esneklik ölçümleri C7-T5 referans noktaları kullanılarak yapıldı. Propriyosepsiyon duyusu dijital inklinometre ile aktif repozisyon testi ile değerlendirildi ve ölçümler 60-90-120ㅇ hedef omuz abdüksiyon açısında yapıldı. Verilerin analizi gruplar arası ve grup içi olmasına göre Mann Whitney-U testi ve Wilcoxon Signed Ranks test kullanılarak yapıldı. Çalışmamız sonucunda tutuş kolu omuz abdüktör kaslarının kuvvetinin çekiş koluna göre, çekiş kolu omuz addüktör kaslarının kuvvetinin tutuş koluna göre daha fazla olduğu, çekiş kolu omuz eksternal rotatör kaslarının esnekliğinin daha fazla olduğu belirlendi $(p<0,05)$. Çekiş kolu ve tutuş kolunun omuz propriosepsiyon duyusu ve internal rotatör kaslarının esnekliğinin birbirine benzer olduğu belirlendi $(p>0,05)$. Kadın ve erkek sporcuların çekiş kolu ve tutuş kolu izometrik kas kuvvetinin erkekler lehine farklı olduğu $(p<0,05)$, eksternal rotatör kaslarının esnekliğinin kadınlar lehine farklı olduğu $(p<0,05)$, internal rotatör kaslarının esnekliği ve propriosepsiyon duyusunun ise cinsiyetler arasında birbirine benzer olduğu belirlendi $(p>0,05)$. Okçularda tutuş kolu omuz abdüktör ve çekiş kolu omuz addüktör kaslarının izometrik kas kuvveti ile çekiş kolu omuz eksternal rotatör kaslarının esnekliğinin diğer tarafa göre daha fazla olduğu belirlendi. Erkek sporcuların omuz abdüktör ve addüktör kaslarının izometrik kas kuvvetinin kadın sporculara göre, kadın sporcuların omuz eksternal rotatör kaslarının esnekliğinin erkek sporculara göre daha fazla olduğu belirlendi.

Anahtar Kelimeler: İokinetik, Internal rotasyon, Eksternal rotasyon, Aktif repozisyon hissi

\section{ABSTRACT}

The aim is to examine isometric muscle strength, flexibility and proprioception sense of shoulder joint of bow and drawing arm in archers. Twenty-one archers (9-female, 12-male) in national team included in study. Isometric muscle strength of shoulder abductoradductor muscles of athletes evaluated with IsoMed2000 device at 90 o abduction angle. Flexibility measured using C7-T5 reference points. The proprioception sensation evaluated by digital inclinometer with active reposition test and the measurements performed at 60 90 - 120 o target shoulder abduction angle. The data between groups analyzed by using Mann Whitney-U test and within groups by using Wilcoxon Signed Ranks test. Findings of study showed strength of bow arm shoulder abductor muscles was higher than drawing arm, strength of drawing arm shoulder adductor muscles was higher than bow arm, and external rotator muscles flexibility of drawing arm shoulder was higher than bow arm $(p<0.05)$. Shoulder proprioception sense and flexibility of internal rotator muscles of bow arm and drawing arm were similar $(\mathrm{p}>0.05)$. Male and female athletes' bow and drawing arm isometric muscle strength is different in favor of male archers $(p<0,05)$, flexibility of external rotator muscles is different in favor of female archers $(p<0,05)$, flexibility of internal rotator muscles and proprioception sense between gender found to be similar $(p>0.05)$. It is determined isometric muscle strength of bow arm shoulder abductor and drawing arm shoulder adductor muscles in archers was higher than other side. It is determined isometric muscle strength of shoulder abductor and adductor muscles of male athletes was higher compared to female athletes, and flexibility of shoulder external rotator muscles of female athletes was higher than male athletes.

Key Words: Isokinetic, Internal rotation, External rotation, Active repositioning sensation 


\section{GíRIŞ}

Okçuluk sporu, vücudun üst bölümünü özellikle de omuz kuşağı kaslarının kuvvet ve dayanıklılığını gerektiren statik bir spordur (Ertan ve diğ., 2003). Okçuluk sporunda isabetli atış, yüksek düzeyde vücut kontrolü, beceri ve odaklanmanın yanı sıra duruş, çekiş, nişan alma, atış ve atışın devam ettirilmesi gibi atışı oluşturan tüm parçaların senkronize bir şekilde tekrarlanabilme yeteneğini gerektirmektedir (Konttinen ve diğ., 2000). Atış sırasında postural salınımda ne gibi değişimlerin meydana geldiği ve bu değiş̧imlerin atış isabetinin derecesi arttıkça nasıl değiştiği atış performansı açısından büyük önem taşımaktadır. İsabetli bir atışın gerçekleşmesi için nişan alınması, kolların ve posturün sabitlenmesi gerekmektedir (Şimşek ve Ertan 2011). Posturün sabitlenebilmesi postural kontrole bağlıdır ve postural kontrol vizüel, vestibüler ve sensoriomotor yapılardan gelen bilgilerle sağlanır (Horak, 2006). Sensoriomotor bilgi eklem stabilitesini sağlamaya yönelik duyusal, motor ve santral entegrasyon işlemini tanımlar (Horak, 2006) Burada yer alan duyusal bileşeni propriyosepsiyon (eklem pozisyon hissi), motor bileşeni ise kassal kontrol oluşturmaktadır. Her ikisi birden postural kontrolün sağlanması için önemlidir (Kocahan ve diğ., 2018).

Okçuluk sporunda iyi bir çekiş, nişan alma ve isabetli bir atış için kas kuvveti ve dayanıklılı̆ı da ön plandadır. Ertan ve diğg. (2005) yaptıkları EMG çalı̧̧maları ile sırt kasları, omuz kemeri kasları, önkol ve parmak kaslarının güç ve aktivasyonunun atış performansındaki önemini ortaya koymuşlardır (Ertan ve diğ., 2005). Araştırmalar uluslararası bir etkinlikte, bir erkek okçunun her bir atışta $45 \mathrm{~kg}$ kuvvetle yay çektiğini ve ortalama dört gün süren bir müsabakada günde en az 75 atış yaptığını belirtmektedir (Sezer ve diğ., 2017). Bu durumda bir okçuluk sporcusu bağ ve kas yapılarına, günde yaklaşık $1546 \mathrm{~kg}$ yük bindirmektedir. Oluşan bu kuvvetin uzun süreli devam ettirilmesi için izometrik kontraksiyonun sürdürülmesinin önemli olduğu düşünülmektedir (Sezer ve diğ., 2017). Bir ok atış1 tam çekişi, nişan almayı ve son olarak serbestlemeyi içermektedir (Kolayiş ve Mimaroğlu 2008). Çekiş esnasında çekiş kolunu sirta ve skapulaya bağlayan kaslar birlikte hareket ederek kuvvet ortaya çıkarırlar. Tam bir çekişin sağlanabilmesi için omuz ekleminin hareketliliğinin tam olması, kasların optimal uzunlukta olması ve böylece skapula ve sırt kaslarının kuvvetini omuza aktarabilmesi önemlidir. Aynı zamanda okun bırakılışı esnasında aksi yönde olan kuvvetin karşılanması çekiş kolunun bırakılış esnasında geriye doğru savrulmasını engelleyerek postural salınıma engel olacaktır (Kolayiş ve Mimaroğlu 2008). İsabetli bir atış omuz, sırt, kol ve el bileğinin koordineli ve tam aktivasyonu ile gerçekleşmektedir (Leroyer ve diğ., 1993). Bu durum okçularda omuz ekleminin kas kuvvetinin, esnekliğinin ve propriosepsiyon duyusunun optimal düzeyde olmasını gerektirir.

Literatürde, asimetrik spor yapan sporcularda spor yapılan taraf ile diğer taraf arasında kas kuvvetinin farklı olduğu (Kocahan ve diğ., 2018; De Lira ve diğ., 2019), dominant olarak kullanılan ekstremitenin hareket açıklığının daha fazla olduğu belirtilmektedir (Mair ve diğ., 2004). Ayrıca defalarca tekrar edilen hareketlerin o ekleme ait propriyosepsiyon duyusunu ve kas kuvvetini geliştireceği de bildirilmektedir (Rogol ve diğ., 1998). Okçularda bu durum dikkate alındığında atış esnasında özellikle omuz abdüktör ve addüktör kaslarının kuvveti, omuz ekleminin esnekliği ve omuz ekleminin propriosepsiyon duyusu önem arz edecektir. Ancak okçularda kas kuvveti, esneklik ve propriosepsiyon duyusu gibi spor performansını etkileyen faktörleri araştıran ve bu parametreleri çekiş kolu-tutuş kolu ve cinsiyet açısından inceleyen çalışmalar oldukça sınırlıdır (Ertan ve diğ., 2003, Kolayiş ve Mimaroğlu 2008). Okçularda çekiş kolu ve tutuş kolu ile kadın ve erkek arasında var olabilecek farkı ölçmek, okçularda gereken fiziksel nitelikleri anlamamızı büyük ölçüde arttıracak, böylece her ekstremiteye ve cinsiyete özgü farklı hedefler içeren antrenman uygulamaları yapılmasına olanak sağlayacaktır. Literatürdeki bilgiler ışığında okçuların aynı hareketi defalarca tekrar etmeleri nedeniyle, çekiş kolu ile tutuş kolu kas kuvveti, omuz esnekliği ve propriyosepsiyon duyusu arasında farklılık olabileceği ve kadın ile erkek sporcularda bu özellikler açısından farklılık olabileceği hipotezi ortaya çıkmaktadır. Bu nedenle bu çalışmanın amacı 
okçularda çekiş kolu ile tutuş kolunun ve kadın ile erkeklerin omuz izometrik kas kuvveti, esneklik ve propriyosepsiyon duyusunun incelenmesidir.

\section{YÖNTEM}

Araştırma Grubu: Araştırmaya milli takım düzeyinde 25 okçu (10 kadın, 15 erkek) davet edildi. Çalışmaya dâhil edilme kriterleri; en az 3 yıldır profesyonel olarak okçuluk sporcusu olmak ve çalışmaya katılmaya gönüllü olmak olarak belirlendi. Çalışmadan dışlama kriterleri; üst ekstremite ile ilgili geçirilmiş operasyon ve spor yaralanması durumu, skolyoz varlığı, boyun, omuz veya önkolda ağrı şikâyetinin olması ve herhangi bir akut ya da kronik spor yaralanması olması olarak belirlendi. Çalışmaya katılma kriterlerine uyan ve çalışmaya katılmayı kabul eden 21 sporcuya çalışma hakkında bilgi verilerek imzalı onamları alındı. Çalışmanın yapılabilmesi için Üniversite Sosyal ve Beşeri Bilimler Etik Kurulundan gerekli izin alındı (Karar no: 13.02.2019-05) ve çalışma Helsinki Deklarasyonu 2008 Prensipleri’ne uygun olarak yapıld1.

Çalışma kriterlerine uyan sporcuların demografik bilgileri alındıktan sonra vücut ağırlığı ölçümleri Tanita MC-980 marka analiz cihazı ile 12 saat açlık sonrasında yapıldı. Sporcuların boy uzunluğu, ayaklar yan yana ve baş frankfort düzlemde (göz üçgeni ve kulak kepçesi üstü aynı hizada) iken bireyin dik durması sağlanarak yönteme uygun bir şekilde SECA marka (Mod.220, Germany) stadiometre ile ölçüldü. Boy ve vücut ağırlığı bilgileri kullanılarak vücut kütle indeki değerleri hesaplandı. Sporcuların yaşları, spor yılı bilgileri sporculara sorularak kaydedildi. Değerlendirmelerde ilk önce omuz propriosepsiyon değerlendirmesi, ardından omuz internal ve ekstrenal rotatör kaslarının esneklik değerlendirmesi yapıldı. Aynı gün öğleden sonra omuz izometrik kas kuvvet ölçümü yapıldı. Sporcuların tanımlayıcı istatistikleri Tablo1'de verildi.

Tablo 1: Okçuların tanımlayıcı verilerinin cinsiyetler arası karşılaştırması

\begin{tabular}{llll}
\hline & $\begin{array}{l}\text { Kadın } \\
(\mathbf{n = 9})\end{array}$ & $\begin{array}{l}\text { Erkek } \\
(\mathbf{n = 1 2})\end{array}$ & $\mathbf{p}$ \\
\hline Yaş (yıl) & $17,11 \pm 2,76$ & $17,42 \pm 2,07$ & 0,917 \\
Boy (cm) & $163,94 \pm 3,47$ & $176,79 \pm 3,84$ & $\mathbf{0 , 0 0 0 *}$ \\
Vücut Ăğırlı̆ı̆ (kg) & $57,17 \pm 9,73$ & $71,06 \pm 5,09$ & $\mathbf{0 , 0 0 2 *}$ \\
Vücut Kütle İndeksi (kg/m $\left.\mathbf{m}^{\mathbf{2}}\right)$ & $21,18 \pm 2,78$ & $22,75 \pm 1,75$ & 0,082 \\
Spor yılı (yıl) & $5 \pm 1,5$ & $6 \pm 2,5$ & 0,702
\end{tabular}

*Mann Whitney-U Testine göre $\mathrm{p}<0.05, \mathrm{X} \pm \mathrm{SS}$ : Ortalama \pm Standart Sapma

\section{Verilerin Toplanması}

Propriosepsiyon Duyusunun Değerlendirilmesi: Propriosepsiyon duyusunu değerlendirmek için dijital inklinometre (Dualer IQ Pro, Jtech Medical Industries) kullanıldı. Değerlendirme her iki üst ekstremite için ayrı ayrı yapıldı. Omuz eklemi propriosepsiyon hissi aktif repozisyon testi kullanılarak 60, 90 ve 120 derecelik açılarda üçer tekrarlı olarak yapıldı. Katılımcı kollukları olmayan bir sandalyeye ayakları yerle tam temasta dizleri 90 derece fleksiyonda dik olarak oturtuldu. Gözler bir bant yardımıyla kapatıldı. Dijital inklinometre deltoid kasının humerus üzerine yapışma yerine (insersio) yerleştirildi. Sporcunun kolu testi yapan fizyoterapist tarafından 0 derece başlangıç pozisyonundan hedef açı olan $60,90,120^{\circ}$ abdüksiyon açılarına getirilip, sporcunun bu pozisyonu öğrenmesi için 5 sn bekletildi ve tekrar başlangıç pozisyonuna yerleştirildi. Daha sonra katılımcıdan kolunu aktif olarak daha önce öğretilen 
hedef açıya getirmesi istendi ve bu test her hedef açı için 3 defa tekrar edildi. Test sonrasında her hedef açı için, sporcunun bulduğu üç açının ortalaması alındı. Aynı işlemler diğer kol için de aynı şekilde gerçekleştirildi (Kocahan ve diğ., 2018).

Internal ve Eksternal Rotatör Kasların Esnekliğinin Değerlendirilmesi: İnternal ve eksternal rotasyon mobilite (esneklik) ölçümü için sporcunun 7. servikal vertebra spinöz çıkıntısı (C7) ve 5. torakal vertebra spinöz çıkıntısı (T5) referans noktalar olarak tespit edildi. Omuz internal rotatör kaslarının esnekliğini değerlendirmek için sporcudan başparmak aşağı gösterecek şekilde kolunu boynunun arkasına götürerek maksimum eksternal rotasyon yapmasını istendi ve sporcunun başparmağının ucu ile T5 arasındaki mesafe mezura ile ölçüldü. Omuz eksternal rotatör kaslarının esnekliğini değerlendirmek için sporcudan başparmağı yukarı gösterecek şekilde kolunu belinin arkasından maksimum internal rotasyona yapması istendi ve sporcunun başparmağının ucu ile C7 arasındaki mesafe mezura ile ölçüldü (Hayes ve diğ., 2001; Edwards ve diğ., 2002).

İzometrik Kas Kuvvetinin Dĕgerlendirilmesi: İzometrik kas kuvveti IsoMed 2000 (D.\& R. Ferstl GmbH, Hemau, Almanya) cihazı ile değerlendirildi. Test öncesinde sporculara 10 dakika boyunca bisiklet ergometresi 60 devir/dk hızda resiprokal olarak ısınma egzersizi yaptırıldı. Testler oturma pozisyonunda uyguland1. Pivot nokta, akromionu arkadan görecek şekilde ve IsoMed 2000 kullanıcı kılavuzunda belirtilen açılarda ayarlandı. Sporcuların kol boyuna göre cihaz ayarlamaları yapıldı ve ekstremiteleri $90^{\circ}$ abdüksiyon pozisyonuna yerleştirildi. Sporcunun diğer ekstremite ve lumbal bölgeden destek almaması için uygun cihaz ekleriyle sabitlendi. Bu pozisyonda sporculardan abdüksiyon hareketini izometrik olarak yapmaları istendi. İlk test kayda alınmayıp, ardından maksimum kuvvette yapılan üç izometrik test sonucunun ortalama kuvvet (OK) değeri ve rölatif olarak karşılaştırma yapabilmek için sporcuların vücut ağırlıklarına oranı $(\mathrm{OK} / \mathrm{kg})$ istatistiksel analizde kullanıldı. Aynı işlem sporcu dinlendikten sonra addüksiyon hareketi için de uygulandı. Bu prosedür her iki kolda sırasıyla takip edildi (Kocahan ve dĭ̆., 2018).

İstatistiksel Analiz: İstatistiksel analizler için SPSS 20.0 paket programı kullanıldı. Çekiş kolu ve tutuş kolunun kas kuvveti, esneklik ve propriosepsiyon duyusunun karşılaştırılmasında Wilcoxon Signed Ranks Test, cinsiyetler arası karşılaştırmada Mann Whitney U testi kullanıldı. Anlamlılık düzeyi için $\mathrm{p}<0.05$ kabul edildi.

\section{BULGULAR}

Kadın ve erkek sporcuların yaş, vücut kütle indeksi ve spor yılları arasında fark olmadığı belirlenirken (p>0,05), boy ve vücut ağırlıklarının erkekler lehine olduğu belirlendi $(\mathrm{p}<0,05)$ (Tablo 1).

Tüm sporcuların çekiş kolu ve tutuş kolları karşılaştırıldığında; tutuş kolu omuz abdüktör kaslarının kuvvetinin çekiş koluna göre, çekiş kolu omuz addüktör kaslarının kuvvetinin tutuş koluna göre daha fazla olduğu, çekiş kolu omuz eksternal rotatör kaslarının esnekliğinin daha fazla olduğu belirlendi $(p<0,05)$. Çekiş kolu ve tutuş kolunun omuz propriosepsiyon duyusu ve internal rotatör kaslarının esnekliklerinin birbirine benzer olduğu belirlendi $(p>0,05)($ Tablo 2).

Tablo 2: Okçuların çekiş kolları ve tutuş kollarının izometrik kas kuvveti, propriosepsiyon duyusu ve kassal esnekliğin karşılaştırması

\begin{tabular}{llll}
\hline Okçular $(\mathbf{n = 2 1})$ & Çekiş kolu & Tutuş kolu & p \\
\hline Omuz İzometrik Kas Kuvveti (Nm) & & & $0,028^{*}$ \\
\hline $\mathbf{9 0}^{\mathbf{0}}$ Abd (OK) & $53,61 \pm 18,94$ & $56,55 \pm 18,16$ & $0,021^{*}$ \\
$\mathbf{9 0}^{\mathbf{0}}$ Abd (OK/kg) & $0,81 \pm 0,22$ & $0,86 \pm 0,19$ & $0,001^{*}$ \\
$\mathbf{9 0}^{\mathbf{0}}$ Add (OK) & $71,90 \pm 27,33$ & $62,23 \pm 23,59$ & $0,001^{*}$ \\
$\mathbf{9 0}^{\mathbf{0}}$ Add (OK/kg) & $1,09 \pm 0,33$ & $0,94 \pm 0,27$ & \\
\hline
\end{tabular}




\section{Omuz Esnekliği (cm)}

\begin{tabular}{|c|c|c|c|}
\hline Eksternal Rotasyon & $0,72 \pm 5,34$ & $3,20 \pm 4,54$ & $0,001 *$ \\
\hline İnternal Rotasyon & $5,49 \pm 5,59$ & $6,07 \pm 3,96$ & 0,575 \\
\hline
\end{tabular}

Omuz Propriosepsiyon Duyusu (derece)

\begin{tabular}{|c|c|c|c|}
\hline $60^{\circ}$ Abd & $5,23 \pm 3,68$ & $5,97 \pm 4,49$ & 0,313 \\
\hline $90^{\circ}$ Abd & $4,95 \pm 3,45$ & $3,63 \pm 2,42$ & 0,211 \\
\hline $120^{\circ} \mathrm{Abd}$ & $4,57 \pm 3,40$ & $5,06 \pm 3,84$ & 0,821 \\
\hline
\end{tabular}

* Wilcoxon Signed Ranks Testine göre p<0.05, OK: Ortalama kuvvet, OK/kg: Rölatif kuvvet, Abd: Abdüksiyon, Add: Addüksiyon

Kadın ve erkek sporcuların çekiş kolu ve tutuş kolu izometrik kas kuvvetinin erkekler lehine farklı olduğu (p<0,05), eksternal rotatör kaslarının esnekliklerinin kadınlar lehine farklı olduğu $(p<0,05)$, internal rotatör kaslarının ve propriosepsiyon duyusunun ise birbirine benzer olduğu belirlendi ( $\mathrm{p}>0,05)$ (Tablo 3$)$.

Tablo 3: Okçuların çekiş kolu izometrik kas kuvveti, propriosepsiyon duyusu ve kassal esnekliğin cinsiyetler arası karşılaştırması

\begin{tabular}{|c|c|c|c|c|}
\hline & & $\begin{array}{l}\text { Kadın } \\
(n=9)\end{array}$ & $\begin{array}{l}\text { Erkek } \\
(n=12)\end{array}$ & $\mathbf{p}$ \\
\hline \multicolumn{5}{|c|}{ Omuz İzometrik Kas Kuvveti (Nm) } \\
\hline \multirow[t]{4}{*}{ Çekiş Kolu } & $90^{\circ}$ Abd (OK) & $37,00 \pm 7,45$ & $66,06 \pm 14,72$ & $0,000 *$ \\
\hline & $90^{\circ} \mathrm{Abd}(\mathrm{OK} / \mathrm{kg})$ & $0,65 \pm 0,11$ & $0,93 \pm 0,20$ & $\mathbf{0 , 0 0 5 *}$ \\
\hline & $90^{\circ}$ Add (OK) & $48,56 \pm 9,70$ & $89,40 \pm 22,58$ & $0,000 *$ \\
\hline & $90^{\circ}$ Add (OK/kg) & $0,87 \pm 0,20$ & $1,26 \pm 0,31$ & $\mathbf{0 , 0 0 3} *$ \\
\hline \multirow[t]{4}{*}{ Tutuş Kolu } & $90^{\circ} \operatorname{Abd}(\mathrm{OK})$ & $40,39 \pm 7,45$ & $68,67 \pm 13,60$ & $0,000 *$ \\
\hline & $90^{\circ}$ Abd (OK/kg) & $0,71 \pm 0,09$ & $0,97 \pm 0,18$ & $\mathbf{0 , 0 0 3 *}$ \\
\hline & $90^{\circ}$ Add (OK) & $42,67 \pm 11,07$ & $76,91 \pm 19,35$ & $\mathbf{0 , 0 0 0 *}$ \\
\hline & $90^{\circ}$ Add (OK/kg) & $0,75 \pm 0,17$ & $1,08 \pm 0,24$ & $0,001 *$ \\
\hline \multicolumn{5}{|c|}{ Omuz Esnekliği (cm) } \\
\hline \multirow[t]{2}{*}{ Çekiş Kolu } & Eksternal Rotasyon & $-1,71 \pm 3,55$ & $2,55 \pm 5,85$ & 0,041* \\
\hline & İnternal Rotasyon & $7,97 \pm 1,74$ & $3,63 \pm 6,76$ & 0,129 \\
\hline \multirow[t]{2}{*}{ Tutuş Kolu } & Eksternal Rotasyon & $1,42 \pm 3,97$ & $4,53 \pm 4,63$ & $0,049 *$ \\
\hline & İnternal Rotasyon & $7,49 \pm 2,16$ & $5,01 \pm 4,72$ & 0,422 \\
\hline \multicolumn{5}{|c|}{ Omuz Propriosepsiyon Duyusu (Derece) } \\
\hline \multirow[t]{3}{*}{ Çekiş Kolu } & $60^{\circ} \mathrm{Abd}$ & $5,24 \pm 4,19$ & $5,22 \pm 3,45$ & 0,917 \\
\hline & $90^{\circ} \mathrm{Abd}$ & $5,78 \pm 3,48$ & $4,33 \pm 3,45$ & 0,422 \\
\hline & $120^{\circ} \mathrm{Abd}$ & $6,07 \pm 4,02$ & $3,45 \pm 2,46$ & 0,111 \\
\hline \multirow[t]{3}{*}{ Tutuş Kolu } & $60^{\circ} \mathrm{Abd}$ & $5,98 \pm 5,64$ & $5,97 \pm 3,69$ & 0,651 \\
\hline & $90^{\circ} \mathrm{Abd}$ & $4,00 \pm 3,27$ & $3,35 \pm 2,46$ & 0,808 \\
\hline & $120^{\circ} \mathrm{Abd}$ & $5,04 \pm 4,48$ & $5,07 \pm 3,48$ & 0,972 \\
\hline
\end{tabular}

\footnotetext{
* Mann Whitney-U Testine göre $\mathrm{p}<0.05$, OK: Ortalama kuvvet, OK/kg: Rölatif kuvvet, Abd: Abdüksiyon, Add: Addüksiyon
} 


\section{TARTIŞMA}

Okçularda çekiş kolu ile tutuş kolunun ve kadın ile erkeklerin omuz izometrik kas kuvveti, esneklik ve propriyosepsiyon duyusunun incelenmesi amacıyla gerçekleştirdiğimiz çalışmamız sonucunda okçularda çekiş kolu ve tutuş kolunda; tutuş kolu omuz abdüktör kaslarının ve çekiş kolu omuz addüktör kaslarının kuvvetinin fazla olduğu, çekiş kolu omuz eksternal rotatör kaslarının esnekliğinin fazla olduğu belirlendi. Çekiş kolu ve tutuş kolunun omuz propriosepsiyon duyusu ve internal rotatör kaslarının esnekliğinin birbirine benzer olduğu belirlendi. Aynı zamanda erkek sporcuların çekiş kolu ve tutuş kolu kas kuvvetinin kadın sporculardan daha fazla olduğu, kadın sporcuların eksternal rotatör kaslarının erkek sporculara göre daha esnek olduğu, propriosepsiyon duyularının ve internal rotatör kaslarının esnekliklerinin ise her iki cinsiyette benzer olduğu belirlendi.

Literatürde çalışmamıza benzer olarak, sporcularda baskın olarak kullanılan ve kullanılmayan ekstremitelerin kas kuvveti, eklem hareket genişliği ve propriosepsiyon duyusunu inceleyen birçok çalışma mevcuttur (Rogol ve diğ., 1998; Mair ve diğ., 2004; Crockett ve diğ., 2002; Reagan ve diğ., 2002; Osbahr ve diğ., 2002; Janwantanakul ve diğ., 2001; Safran ve diğ., 2001; Ellenbecker ve diğ., 2002; Ihalainen ve diğ., 2016). Yapılan bu çalışmalarda sporda baskın olarak kullanılan ekstremitenin kas kuvvetinin, esnekliğinin ve propriosepsiyon duyusunun daha fazla olduğu bulunmuştur. $\mathrm{Bu}$ durum kasların daha fazla kullanılması ile açıklanmaktadır. Literatüre benzer olarak bizim çalışmamızda da okçuların tutuş kolu omuz abdüktör kaslarının kuvvetinin çekiş koluna göre daha fazla olduğu belirlendi. Tutuş kolunda yayın sabit olarak zemine paralel tutulması tutuş kolunun omuz abdüktör kaslarının kuvvetli olmasını açıklayabilir. Ayrıca kiriş çekme hareketi sırasında çekiş kolunda meydana gelen hareket horizontal abdüksiyon ile başlar ve bir miktar addüksiyon hareketi ile tamamlanır. Sporcunun bu hareketi bir dirence karşı yapması çekiş kolunun omuz addüktör kaslarının daha kuvvetli olmasını açıklayabilir. Ancak bu konu ile ilgili yapılacak ve kiriş çekme sırasında hangi kasların aktif olduğunu belirleyecek elektromyografik ve biyomekanik çalışmalara ihtiyaç olduğunu düşünmekteyiz.

Esneklik hem spor performansını etkileyen hem de kas yaralanmaları ile ilişkisi olan bir parametredir. Esnekliğin kas kuvveti ile ilişkili olduğu ve esneklik arttıkça kas kuvvetinin azalma yönünde olduğu belirtilmektedir (Alonso ve diğ., 2009; Brockett ve diğ., 2004). Esneklik birçok fiziksel uygunluk parametresi ile ilişkili olabilirken, eklem hareket açıklığı ile doğrudan ilişkisi söz konusudur (Lopes ve diğ., 2017). Çalışmamız sonucunda çekiş kolu omuz eksternal rotatör kaslarının esnekliğinin tutuş koluna göre daha fazla olmasının, çekiş kolunun daha büyük bir eklem hareket açıklığı ile kullanılmasından ve tutuş kolunun ok atma sırasında stabil olmasından kaynaklandığını düşünmekteyiz.

Propriyosepsiyon duyusu da tekrarlı açık ve kapalı kinetik egzersizler yardımıyla geliştirilebilir (Safran ve diğ., 2001). Tekrarlı egzersizler ile nöromusküler kontrol, kas kuvveti ve kinestezi duyusu artış gösterir. Böylece hem aktive olan kas iğciklerinin sayısı artar hem de mekanoreseptörlere olan veri girişi artarak propriosepsiyon duyusu da arttırılmış olur. (Dilek ve diğ., 2016; Safran ve diğ., 2001). Çalışmamızda iki kolun propriosepsion duyusu arasında fark olmamasını okçuluk sporunda hem açık hem de kapalı kinetik hareketlerin yer alması ve her iki kolun da fonksiyonel olarak aktif kullanılmasına bağlayabiliriz.

Literatürde kadın ve erkekleri bazı parametreler açısından karşılaştıran birçok çalışma mevcuttur (Monteiro ve diğ., 2016; Janssen ve diğ., 2000; Dallinga ve diğ., 2016; Inskip ve diğ., 2007; Aslan ve Çınar, 2012; Sell ve Lephart, 2018). Cinsiyetler arasında kas kuvvetini inceleyen çalışmalarda erkeklerin kadınlara göre daha fazla kas kütlesine ve rölatif kas kuvvetine sahip olduğu belirtilmektedir (Monteiro ve diğ., 2016; Janssen ve diğ., 2000). Erkeklerin kadınlara göre kemik çapı ve uzunluğu, kas kütlesi, boy uzunluğu ve vücut ağırlığı daha fazla iken vücut yağ oranı daha düşüktür (Borms, 1986; Carter, 1981). Aynı zamanda erkeklerin pelvisi daha dar, göğüs çevresi daha geniş, kubital açı ve kuadriseps açısı daha dardır (Borms, 1986; Carter, 1981). Bu farklılıkları yaratan ana sebep intrauterin hayattan itibaren erkeğin testesteron 
hormonu, kadının ise östrojen hormonunun baskın etkisine maruz kalmasıdır (Borms, 1986; Carter, 1981). Bu hormonal etki aynı zamanda kas lif tipi dağılımı ve enerji yolaklarındaki enzim farklılıklarına da etki ederek erkeklerin patlayıcı kuvvetinin daha iyi olmasına neden olmaktadır (Borms, 1986; Carter, 1981; Nimphius ve diğ., 2019). Biz de çalışmamızda literatürde var olan bilgilerle uyumlu olarak erkek sporcuların total ve rölatif kas kuvvetinin kadın sporculardan fazla olduğunu belirledik.

Cinsiyetler arasında propriyosepsiyon duyusunu karşılaştıran çalışmalar oldukça sınırlı olup, yapılan çalışmalar genellikle yaralanmalardan sonra diz ve ayak bileği eklemi propriyosepsiyon duyusu ile ilgilidir (Dallinga ve diğ.,2016; Sell ve Lephart, 2018). Bu çalışmalar yaralanma sonrası propriosepsiyon duyusunu değerlendiren ya da proprisepsiyon duyusunu statik ve dinamik postural stabilite ile değerlendiren çalışmalardır (Dallinga ve diğ.,2016; Sell ve diğ., 2018). Bizim çalışmamıza dâhil edilen sporcuların herhangi bir yaralanma durumunun olmaması ve propriosepsiyon duyusunun inklinometre ile değerlendirilmiş olması nedeniyle çalışmamızın sonuçlarının daha objektif olduğunu söyleyebiliriz. Nitekim Kocahan ve diğ. (2018) herhangi bir yaralanması olmayan tabanca atıcılarının omuz propriosepsiyon duyusunu inceledikleri araştırmada kadın ve erkek atıcıların proprioseptif duyularının benzer olduğunu bulmuşlardır (Kocahan ve diğ., 2018). Çalışmamız bu çalışmaya benzerlik göstermektedir.

Kadın ve erkeklerin esnekliğinin karşılaştırıldığı birçok çalışma mevcuttur ve bu çalışmalarda kadınların anatomik, fizyolojik ve hormonal farklılıklardan dolayı daha esnek olduğu belirtilmektedir (Inskip ve diğ., 2007; Aslan ve Çınar, 2012). Literatürde var olan bilgilere paralel olarak bizim çalışmamızda da omuz eksternal rotasyon esnekliğinin kadınlarda erkeklere oranla daha fazla olduğu, ancak internal rotasyon esnekliklerinin erkelerle benzer olduğu belirlendi. Çalışmamızda eksternal rotatör kaslarının esnekliğinin kadınlarda fazla olması, internal rotatör kaslarının esnekliklerinin ise iki cinsiyet arasında benzer olması durumu okçuluk sporcularında cinsiyetler arasında omuz ekleminin esneklik farklılıklarını tam olarak ortaya koymadığı için, daha çok sporcu ile yapılacak daha geniş çalışmalara ihtiyaç olduğunu düşünmekteyiz.

\section{SONUÇ VE ÖNERILER}

Çalışmamızda sporcuların tutuş kolu omuz abdüktör kas kuvvetinin ve çekiş kolu omuz addüktör kas kuvvetinin diğer ekstremiteye göre fazla olduğu; çekiş kolu omuz eksternal rotatör kas esnekliğinin daha fazla olduğu belirlendi. Çekiş kolu ve tutuş kolunun omuz propriosepsiyon duyusu ve internal rotatör kaslarının esnekliğinin birbirine benzer olduğu belirlendi. Ayrıca, çekiş kolu ve tutuş kolu izometrik kas kuvvetinin erkeklerde daha fazla olduğu, çekiş kolu eksternal rotatör kaslarının esnekliklerinin kadınlarda daha fazla olduğu belirlendi. Çalışmamızın sonuçları ekstremite ve cinsiyet bazında var olan farklılıkların belirlenmesine katkı sağlayarak, okçularda ekstremiteye ve cinsiyete özgü hedefler içeren antrenman uygulamaları için referans bilgi oluşturulmasında ve herhangi bir yaralanma durumunda rehabilitasyon stratejilerinin geliştirilmesinde kullanılabilir. 


\section{KAYNAKLAR}

1. Alonso J, McHugh MP, Mullaney MJ, Tyler TF. (2009). Effect of hamstring flexibility on isometric knee flexion angle-torque relationship. Scandinavian Journal of Medicine and Science in Sports, 19(2), 252-256.

2. Aslan CS, Ziynet Ç. (2012). Aktif veya sedanter kadin ve erkek bireylerin seçilmiş fiziksel ve fizyolojik özelliklerinin karşilaştirilmasi. Spor Hekimliği Dergisi, 47(1), 29-36.

3. Brockett CL, Morgan DL, Proske U. (2004). Predicting hamstring strain injury in elite athletes. Medicine and Science in Sports and Exercise, 36(3), 379-387.

4. Borms J. (1986). The child and exercise: An overview. Journal of Sports Sciences, 4(1), 3-20.

5. Carter JE. (1981). Somatotypes of female athletes. (J. Borms, M. Hebbelinck, A. Venerando, Eds.), The Female Athlete (pp. 85-116). Basel, Switzerland: Karger.

6. Crockett HC, Lyndon BG, Kevin EW, Martin LS, Jamie R, Jay O, ve diğ. (2002). Osseous adaptation and range of motion at the glenohumeral joint in professional baseball pitchers, The American Journal of Sports Medicine, 30(1), 20-26.

7. Dilek B, Gulbahar S, Gundogdu M, Ergin B, Manisali M, Ozkan M,ve diğ. (2016). Efficacy of proprioceptive exercises in patients with subacromial impingement syndrome: a single-blinded randomized controlled study. American Journal of Physical Medicine and Rehabilitation, 95(3), 169-182.

8. Dallinga JM, van der Does HT, Benjaminse A, Lemmink KA. (2016). Dynamic postural stability differences between male and female players with and without ankle sprain. Physical Therapy in Sport, 17, 69-75.

9. De Lira CAB, Vargas VZ, Vancini RL, Andrade MS. (2019). Profiling isokinetic strength of shoulder rotator muscles in adolescent asymptomatic male volleyball players. Sports, 7(2), 49.

10. Edwards TB, Bostick RD, Greene CC, Baratta RV, Drez D. (2002). Interobserver and intraobserver reliability of the measurement of shoulder internal rotation by vertebral level. Journal of Shoulder and Elbow Surgery, 11(1), 40-42.

11. Ellenbecker TS, Roetert EP, Bailie DS, Davies GJ, Brown SW. (2002). Glenohumeral joint total rotation range of motion in elite tennis players and baseball pitchers. Medicine and Science in Sports and Exercise, 34(12), 2052-2056.

12. Ertan H, Kentel B, Tümer ST, Korkusuz F. (2003). Activation patterns in forearm muscles during archery shooting. Human Movement Science, 22(1), 37-45.

13. Ertan H, Kentel BB, Tümer ST, Korkusuz F. (2005). Reliability and validity testing of an archery chronometer. Journal of Sports Science and Medicine, 4(2), 95-104.

14. Hayes K, Walton JR, Szomor ZR, Murrell GA. (2001). Reliability of five methods for assessing shoulder range of motion. Australian Journal of Physiotherapy, 47(4), 289-94.

15. Horak FB. (2006). Postural orientation and equilibrium: what do we need to know about neural control of balance to prevent falls?. Age and Ageing, 35 (suppl_2), ii7-ii11.

16. Ihalainen S, Kuitunen S, Mononen K, Linnamo V. (2016). Determinants of elite- level air rifle shooting performance. Scandinavian Journal of Medicine and Science in Sports, 26(3), 266-274.

17. Inskip HM, Godfrey KM, Martin HJ, Simmonds SJ, Cooper C, Sayer AA. (2007). Southampton women's survey study group. Size at birth and its relation to muscle strength in young adult women. Journal of Internal Medicine, 262(3), 368-374.

18. Janssen I, Heymsfield SB, Wang ZM, Ross R. (1985). Skeletal muscle mass and distribution in 468 men and women aged 18-88 yr. Journal of Applied Physiology, 89(1), 81-88.

19. Janwantanakul P, Magarey ME, Jones MA, Dansie BR. (2001). Variation in shoulder position sense at mid and extreme range of motion. Archives of Physical Medicine and Rehabilitation, 82(6), 840-844.

20. Kocahan T, Akinoğlu B, Ünüvar E, Hasanoğlu A. (2018). Havalı tabanca atıcılık sporcularında tetik kolu ve diğer kolun omuz eklemi izometrik kas kuvveti ve propriyosepsiyon duyusunun karşılaştırılması. Turkiye Klinikleri Spor Bilimleri Dergisi, 10 (3),116-122.

21. Eroğlu Kolayiş İ, Mimaroğlu E. (2008). Okçuluk milli takımının antrenman ortamında kalp atım hızı ve nişan alma süresinin atış puanı üzerindeki etkileri. Uluslar arası İnsan Bilimleri Dergisi, 5(1), 1-18.

22. Konttinen N, Landers DM, Lyytinen H. (2000). Aiming routines and their electrocortical concomitants among competitive rifle shooters. Scandinavian Journal of Medicine and Science in Sports, 10(3), 169-177.

23. Leroyer P, Van Hoecke J, Helal JN. (1993). Biomechanical study of the final push- pull in archery. Journal of Sports Sciences, 11(1), 6369.

24. Lopes L, Povoas S, Mota J, Okely AD, Coelho ESMJ, Cliff DP, ve diğ. (2017). Flexibility is associated with motor competence in schoolchildren. Scandinavian Journal of Medicine and Science in Sports, 27(12), 1806-1813. 
25. Mair SD, Uhl TL, Robbe RG, Brindle KA. (2004). Physeal changes and range-of-motion differences in the dominant shoulders of skeletally immature baseball players. Journal of Shoulder and Elbow Surgery, 13(5), 487-491.

26. Monteiro ER, Brown AF, Bigio L, Palma A, dos Santos LG, Cavanaugh MT, ve diğ. (2016). Male relative muscle strength exceeds females for bench press and back squat. Journal of Exercise Physiology Online, 19(5), 79-86.

27. Nimphius S, McBride JM, Rice PE, Goodman-Capps CL, Capps CR. (2019). Comparison of quadriceps and hamstring muscle activity during an isometric squat between strength-matched men and women. Journal of Sports Science and Medicine, 18(1), 101-108.

28. Osbahr DC, Cannon DL, Speer KP. (2002). Retroversion of the humerus in the throwing shoulder of college baseball pitchers. The American Journal of Sports Medicine, 30 (3), 347-353.

29. Reagan KM, Meister K, Horodyski MB, Werner DW, Carruthers C, Wilk K. (2002). Humeral retroversion and its relationship to glenohumeral rotation in the shoulder of college baseball players. The American Journal of Sports Medicine, 30(3), 354-360.

30. Rogol IM, Ernst G, Perrin DH. (1998). Open and closed kinetic chain exercises improve shoulder joint reposition sense equally in healthy subjects. Journal of Athletic Training, 33(4), 315-318.

31. Safran MR, Borsa PA, Lephart SM, Fu FH, Warner JJ. (2001). Shoulder proprioception in baseball pitchers. Journal of Shoulder and Elbow Surgery, 10(5), 438-444.

32. Sell TC, Lephart SM. (2018). Neuromuscular differences between men and women. In ACL Injuries in the Female Athlete. s. 133-152. Springer, Berlin, Heidelberg.

33. Sell TC, Lovalekar MT, Nagai T, Wirt MD, Abt JP, Lephart SM. (2018). Gender differences in static and dynamic postural stability of soldiers in the army's 101st airborne division (Air Assault). Journal of Sport Rehabilitation, 27(2), 126-131.

34. Sezer YS, Çelikel BE, Gür E, Savucu Y. (2017). Okçularin el kavrama kuvvetine birim antrenmanin etkisi effect of unit exercise on hand grip strength of the archers. International Refereed Academic Journal of Sports, Health and Medical Sciences, 24,14-26.

35. Şimşek D, Ertan H. (2011). Postural kontrol ve spor: spor branşlarına yönelik postural sensör-motor stratejiler ve postural salınım. Spormetre Beden Eğitimi ve Spor Bilimleri Dergisi, 9(3), 81-90. 